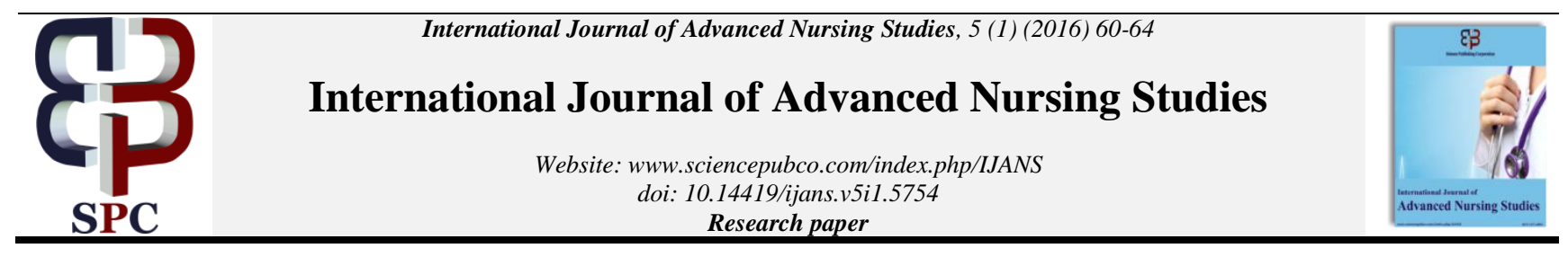

\title{
Esmolol vs. nitroglycerin: attenuating hemodynamic response to laryngoscopy and intubation
}

\author{
Cassie Held* \\ Cassie Held RN BSN CCRN CEN Texas Christian University School of Nurse Nesthesia TCU Box 298626 Fort Worth, TX 76129 \\ *Corresponding author E-mail: c.r.held@tcu.edu
}

\begin{abstract}
Hemodynamic response to laryngoscopy and intubation is a common occurrence with the potential for harmful effects. Many drugs have been utilized throughout the years to attenuate this response with mixed results. This review compares the efficacy of two drugs, esmolol and nitroglycerin, in attenuating hemodynamic response to laryngoscopy and intubation. A systematic review was performed compiling all previous studies detailing the efficacy of esmolol in comparison to nitroglycerin for this purpose. Esmolol was found to consistently attenuate hemodynamic responses of blood pressure and heart rate with greater efficacy than nitroglycerin, and is thus recommended over nitroglycerin for use in this role.
\end{abstract}

Keywords: Esmolol; Hemodynamic; Intubation; Laryngoscopy; Nitroglycerin.

\section{Introduction}

Reid and Brace first described the phenomenon of hemodynamic response to laryngoscopy and intubation in 1940 (Reid \& Brace 1940). They and others established that the induction of anesthesia with associated respiratory tract irritation due to laryngoscopy and intubation often results in a hemodynamic response comprised of symptoms such as hypertension and tachycardia (Reid \& Brace 1940, Kovac 1996, Aghdaii et al. 2015, Sarkilar et al. 2015). Since the description of this phenomenon in 1940, there have been various anesthetic drug combinations and hemodynamic-moderating efforts that researchers have trialed over the years in an effort to attenuate this sudden, and often dramatic, hemodynamic response - several of which are targeted in this review (Singh et al. 1995, van den Berg et al. 1997, Gupta et al. 2009). However, no specific regimen or drug combination has demonstrated consistent and convincing outcomes in the mediation of this response across the majority of patients requiring endotracheal intubation. This is particularly problematic in patients who are already hemodynamically compromised, who have an inability to endure the cardiovascular rigors that such a response dem ands, or who are at increased risk for injury in the presence of hypertension (such as patients experiencing elevated intracranial pressures or patients with unstable aneurysms). In such instances, hemodynamic stability is of paramount importance and thus requires further research. Therefore, the following "Population, Intervention, Comparison, Outcome, Time" (PICOT) question, involving two medications utilized for attenuating exaggerated hemodynamic responses was developed. One of them, nitroglycerin, has been a commonly utilized drug for hemodynamic response control. The other, esmolol, is a newer drug that appears to be an improved option. The developed PICOT is:

$\mathrm{P}$ - In adult patients undergoing the induction of anesthesia with intubation

I - does Esmolol

$\mathrm{C}$ - as compared to nitroglycerin
O - More effectively control hemodynamic responses (heart rate \& blood pressure)

$\mathrm{T}$ - during laryngoscopy and intubation

\section{Methods}

A search was conducted at various databases to maximize potential results. The databases PubMed, EMBASE, and CINAHL were utilized. At each database, the following searches were performed:

1) "esmolol AND nitroglycerin AND induction"

2) "esmolol AND nitroglycerin AND intubation"

3) "esmolol AND nitroglycerin AND anesthesia"

4) "esmolol AND nitroglycerin AND anesthesia AND hemodynamic"

There were surprisingly few results at each search engine. At CINAHL, only one article resulted for each of the above searches performed. In PubMed, the same 3 articles resulted for each of the above searches performed; though in performing the searches "esmolol AND nitroglycerin AND induction" and "esmolol AND nitroglycerin AND anesthesia AND hemodynamic," several additional articles resulted (returning results of 5 articles and 12 articles, respectively). However, the additional resultant articles were not specific to the true nature of the search, which was to ascertain articles that explored the treatment of the exaggerated hemodynamic response noted with the induction of anesthesia and subsequent laryngoscopy and intubation. The single article that CINAHL returned in each of the searches performed was also one of the 3 that PubMed consistently returned.

EMBASE returned significantly more results with the above searches with the exception of the search "esmolol AND nitroglycerin AND intubation," which resulted in 5 articles. This search returned the most applicable results to the intent of the posed PICOT question. Of these 5, only one was the same as those returned in the PubMed searches, and it was not the same article that resulted consistently in the searches performed at CINAHL. With the other search terms utilized, EMBASE returned, at most, 
69 articles, and at the least, 5. In perusing the general content of the articles resulted, the vast majority were not applicable to the intent of the search. Most of the articles addressed the use of esmolol and nitroglycerin for the purpose of inducing a state of intentional hypotension to reduce intraoperative blood loss (known as hypotensive anesthesia), or their role in the intraoperative management of hypertensive states in such disease processes as pheochromocytoma.

As the results returned at each search engine were already quite limited, there was no need for further refinement of the search via such limitations as time frame or language, although the limitation of specific study types (limiting studies to clinical trials or randomized controlled trials) was utilized so as to eliminate articles of lower levels of evidence. The 4 search terms utilized above are the broadest possible key terms in regards to the topic addressed in the stated PICOT. The search results indicate that a limited amount of research has been done regarding the comparison of nitroglycerin and esmolol for the purpose of hemodynamic control upon intubation of an anesthetized patient.

\section{Results}

The first article obtained was a randomized, placebo-controlled, double-blinded study in which the efficacy of intravenous (IV) lidocaine, esmolol, and nitroglycerin were each individually considered for the purpose of attenuating the hemodynamic response of anesthetized patients to laryngoscopy and intubation (Singh et al. 1995). According to the Joanna Briggs Institute, this study method is indicative of a level of evidence of 1.c (Appendix I) (The Joanna Briggs Institute 2013). The researchers randomized 40 patients meeting American Society Anesthesiologists (ASA) I and II health criteria into 4 different groups, utilizing a computergenerated table (Singh et al. 1995). The randomization method was performed according to a double-blinded, placebo-controlled protocol (Singh et al. 1995). Each of the patients was scheduled for a procedure that was considered "general surgery." The 4 groups that subjects were randomized into were as follows: Group 1: saline $5 \mathrm{ml} \mathrm{IV} \mathrm{at} \mathrm{time} 0 \mathrm{~min}$; Group 2: lidocaine $1.5 \mathrm{mg} / \mathrm{kg}$ IV at time 1 minute; Group 3: esmolol $1.4 \mathrm{mg} / \mathrm{kg}$ IV at time 2 minutes; Group 4: nitroglycerin $2 \mathrm{mcg} / \mathrm{kg}$ IV at time 3 minutes (Singh et al. 1995). Each patient was induced with the same anesthesia regimens of thiopental $5 \mathrm{mg} / \mathrm{kg}$, and vecuronium 0.15 $\mathrm{mg} / \mathrm{kg}$ (Singh et al. 1995). Time of induction was considered time 0 minutes. Each patient was administered their respective treatment regimens according to the group to which they had been randomly assigned. Each patient was subsequently intubated, with laryngoscopy beginning at time 3.5 minutes (Singh et al. 1995). Mean arterial pressure (MAP) and HR were recorded every 60 seconds for 20 minutes, and hemoglobin $\mathrm{O}_{2}$ saturations as well as ECG lead $V_{5}$ were monitored continuously (Singh et al. 1995). Statistical analysis revealed that MAP increased significantly in all four treatment groups (control $49 \% \pm 19 \%$, lidocaine $55 \% \pm 26 \%$, esmolol $25 \% \pm 11 \%$, nitroglycerin $45 \% \pm 21 \%$ ), though esmolol was by far the most effective at attenuating the increase in MAP with only a $25 \%$ increase as compared to a $45 \%$ increase noted in nitroglycerin (Singh et al. 1995). The increase in HR was also more effectively controlled by esmolol than in the other variables, with the following results: control $29 \% \pm 4 \%$, lidocaine $52 \% \pm$ $8 \%$, esmolol $20 \% \pm 3 \%$, nitroglycerin $37 \% \pm 8 \%$ (Singh et al. 1995). This data was analyzed via analysis of variance (ANOVA) as well as Student's paired t-test (Singh et al. 1995). An unpaired t-test with Bonferroni's correction was utilized for comparison between treatment groups (Singh et al. 1995). P < 0.05 was considered statistically significant.

Results showed that esmolol was consistently and markedly better at moderating both MAP and HR increases sustained during laryngoscopy and intubation as compared to lidocaine and nitroglycerin (Singh et al. 1995). Lidocaine and nitroglycerin each demonstrated virtually no effect on hemodynamic moderation (Singh et al. 1995).
The study demonstrated many strengths in its manner of organization, as it equalized, as much as possible, the variables to which each patient was exposed. Each patient received not only the same induction agents, but also the same dosing, as based upon their weights. A baseline was established with a placebo group. Each test medication administered was done so at a time in which previous studies had indicated would allow for their maximum effect in conjunction with the timing of laryngoscopy and intubation. The study was conducted in a double-blind manner, with randomized delegation of study participants done by an impartial designator - a computer - thus effectively eliminating study bias.

While the study was well organized and conducted in an unbiased manner, it also appeared to have several weaknesses. First, it was a relatively small study - only 40 participants. When these 40 participants were further divided into their respective test groups, this resulted in just 10 patients being tested in each study group. Second, the study included patients from age 33 to 71 . This is a fairly large age range. Cardiovascular compliance changes drastically with age and could potentially have had an effect on study results. Third, the study did not take into consideration either participant ethnicity or sex. Each of these factors could have potentially been significant, as some ethnic groups have been proven to be more prone to hypertension. Also, according to the American Heart Association, male and female populations show differing propensities for hypertension at varying ages (Go et al. 2013). Therefore, the large age range coupled with the lack of information regarding sex of patients studied, could potentially have a doubly confounding effect on garnered results. Lastly, and perhaps most significantly, the method of drug administration was via IV bolus rather than infusion. While lidocaine's half-life is 1.5-2 hours, both esmolol and nitroglycerin's are a matter of minutes. Therefore, their duration may not have been adequate enough to sufficiently reflect potential effects of the drugs - particularly had they been administered via infusion rather than bolus dose.

The second article was also a randomized control trial consisting of 60 test subjects, establishing it as a study of level 1.c evidence (Gupta et al. 2009, The Joanna Briggs Institute 2013). To qualify for the study, the 60 subjects were deemed to be of ASA I and II health criteria (Gupta et al. 2009). Each was randomly allocated to 1 of 3 groups: Group C: normal saline infusion (control group), Group E: Esmolol hydrochloride infusion $100 \mathrm{mcg} / \mathrm{kg} / \mathrm{min}$, and Group N: Nitroglycerin infusion $0.5 \mathrm{mcg} / \mathrm{kg} / \mathrm{min}$ (Gupta et al. 2009). The infusions were each started 5 minutes prior to induction of anesthesia, and discontinued 5 minutes after intubation, for a total continuous run time of 10 minutes (Gupta et al. 2009). After baseline HR, systolic blood pressure (SBP), diastolic blood pressure (DBP) and MAP were recorded, each patient was administered glycopyrrolate $0.2 \mathrm{mg} \mathrm{IV}$ and pentazocine $0.5 \mathrm{mg} / \mathrm{kg} \mathrm{IV}$ (Gupta et al. 2009). Anesthesia was then induced via thiopentone sodium $1-2 \mathrm{mg} / \mathrm{kg}$ and succinylcholine $1.5 \mathrm{mg} / \mathrm{kg}$ (Gupta et al. 2009). Direct laryngoscopy and intubation was accomplished within 30 seconds in each case (Gupta et al. 2009). Serial measurement of HR, SBP, DBP, and MAP was performed throughout the case (Gupta et al. 2009). Anesthesia was maintained after induction with $66 \%$ nitrous oxide in oxygen and vecuronium bromide (Gupta et al. 2009). Results consistently demonstrated that esmolol was more effective in every measured category at attenuating hemodynamic responses to laryngoscopy and intubation than either the normal saline or nitroglycerin (Gupta et al. 2009).

Statistical analysis was performed utilizing Chi square test and Student's t-test as each were applicable (Gupta et al. 2009). P < 0.05 was considered statistically significant (Gupta et al. 2009). The HR data analysis yielded results where the control group demonstrated a significant increase in HR after intubation, with an associated P-value of $\mathrm{P}<0.001$ (Gupta et al. 2009). The nitroglycerin group also demonstrated a significant increase in HR with an associated $\mathrm{P}$-value of $\mathrm{P}<0.05$ (Gupta et al. 2009). The esmolol group demonstrated no significant increase in HR, and the small changes in HR that were noted were not statistically significant. The changes in SBP and MAP were all statistically significant for the nitroglycerin and esmolol drips, exhibiting P-values of $\mathrm{P}<$ 
0.05 and $\mathrm{P}<0.01$ for SBP, $\mathrm{P}<0.001$ and $\mathrm{P}<0.05$ respectively (Gupta et al. 2009). The data collected in regards to DBP does not reflect any statistically significant results (Gupta et al. 2009). Therefore, esmolol was seen to more effectively attenuate hemodynamic responses in every category than its comparative, nitroglycerin.

This study demonstrated several strengths, some that the preceding article did not. First, and perhaps most importantly, it administered the trial medications in a manner that was tailored to maximize the drug's potential benefits - via infusion rather than bolus dose. Second, the researchers at least made note of the sex of the participants, though they did not perform any data analysis to consider potential confounding issues tied to this particular facet. Third, they also utilized identical induction medications for each case along with a standardized dosing regimen.

This study also displayed several weaknesses. While the researchers did make note of the sex of the participants, stating that there was "no significant difference in mean age, weight and sex ratio in the three groups" (Gupta et al. 2009 p. 1). It is certainly arguable that there is a fairly significant difference in the male to female ratio between the control group and the nitroglycerin group, at a ratio of 7:13 and 2:18, respectively (Gupta et al. 2009). However, whether this had any impact or not is unknown, as the researchers did no data disclosure or analysis relating to the sex of the participants beyond the above statement. It would also appear that this study was not blinded in any way, and could, therefore, possibly be affected by bias. However, the method of administration would have made it difficult to blind the study, as infusion rates would indicate which drug was being administered.

In the final article, 100 study participants undergoing cataract surgery were considered in a randomized control trial, giving it an evidence level of 1.c (Appendix I) (The Joanna Briggs Institute 2013, van den Berg et al. 1997). Unlike the previous 2 studies in which only relatively "healthy" patients were included, this study contained 52 participants who were considered "healthy" and 48 participants who had one or more of the following illnesses: diabetes, hypertension, or ischemic heart disease (van den Berg et al. 1997). The participants were randomized into 5 groups: Group 1: saline (control group), Group 2: magnesium sulfate $40 \mathrm{mg} / \mathrm{kg}$, Group 3: esmolol $4.0 \mathrm{mg} / \mathrm{kg}$, Group 4: lignocaine (lidocaine) 1.5 $\mathrm{mg} / \mathrm{kg}$, Group 5: glyceryl trinitrate (nitroglycerin) $7.5 \mathrm{mcg} / \mathrm{kg}$ (van den Berg et al. 1997). Each medication was given at time of induction of anesthesia (van den Berg et al. 1997). Anesthesia was standardized for every patient. Each patient was assessed for HR, blood pressure (BP), rate-pressure product (RPP), and pressurerate quotient (PRQ) throughout the duration of the procedure. Results showed that esmolol was the most effective at preventing rises in HR and RPP (van den Berg et al. 1997). Nitroglycerin also prevented a rise in RPP, but showed not only an inability to moderate the rise in HR, but in fact, resulted in a tachycardia above that demonstrated in the control group (van den Berg et al. 1997). Magnesium sulfate and lidocaine were equally ineffective at moderating hemodynamic responses to laryngoscopy and intubation, and in fact both demonstrated elevated RPPs as compared to the control group (van den Berg et al. 1997).

Statistical analyses were performed on the data obtained in the HR and MAP groups, using Fisher's exact test, one-way ANOVA, and paired Student t-test. Regarding HR, all variables were found to be statistically significant, have been analyzed via paired Student $t$ test all reflecting P-values of $<0.001$. MAP also demonstrated statistically significant results in all variable groups again utilizing the paired Student t-test and all reflecting P-values of $<0.001$ RPP and PRQ were not statistically analyzed beyond the calculation of standard deviation for all data results.

This study demonstrated several strengths - some of which the other studies did not. First, it was a larger study group than either of the other studies, including a total of 100 participants. Second, this study considered not only healthy individuals, but also individuals with one or more disease processes. While this factor could also be seen as a weakness, as it contributes uncontrolled variables to the study process, the researchers alleviated this po- tential issue by comparing study results between the "healthy" and "unhealthy" groups. Their results indicated that those individuals with one or more of the listed diseases did not yield results that were of any statistically different significance. Finally, as in the other study groups, anesthesia was standardized amongst study participants, so as to eliminate potential confounding hemodynamic effects of varying anesthetics.

This study also demonstrated some weaknesses. Unlike the first study, the times of test drug administration were all at the same time, which did not allow for optimal onset of each drug (allowing each drug to be seen at its time of optimal onset). Unlike the second study, this study was conducted via bolus dosing of the test drugs, not via infusion of the test medications. While this form of administration may have been sufficient for longer-acting medications, such as magnesium sulfate and lidocaine, it may not have been sufficient to fully demonstrate esmolol and nitroglycerin's effects as they have much shorter durations. Finally, it tested a far larger number of variables than either of the other studies, amounting to 5 test groups, in effect testing only 20 patients per test medication. While this may initially appear beneficial, as it allows for greater comparison, it seems unnecessary to test magnesium sulfate in this role, as it has never been utilized for acute episodes of hypertension or tachycardia, nor does it possess pharmacokinetic characteristics amenable to its use in such a role.

\section{Discussion}

Each of the reviewed studies demonstrated data in which esmolol produced maximally attenuated hemodynamic responses in comparison to any other drug tested, regardless of dosing method (bolus vs. infusion). In fact, the raw data displayed in the study by Gupta et al, demonstrated that the esmolol infusion was so effective, that only a minimal amount of variation was noted (Gupta et al. 2009). This lack of statistical significance, while initially appearing to be a negative outcome, is, in fact, affirming when the raw data is reviewed. As Gelman and Stern assert, "Statistical significance is not the same as practical importance, that dichotomization into significant and non-significant results encourages the dismissal of observed differences" (Gelman \& Stern 2006). With this in mind, the observed differences clearly demonstrate the esmolol infusion's superiority at attenuating HR response in comparison to the various other methods tested for the same purpose. Esmolol, regardless of its route of administration, has been shown more effective at attenuating all measured hemodynamic responses when compared to the other drugs tested. The first trial, wherein all variables were found to be of statistical significance, revealed that esmolol boluses demonstrated an overall higher level of efficacy than its counterparts, nitroglycerin and lidocaine. This is most clearly seen in the statistical conclusions presented in the form of standard deviation by the researchers which reflects the percentage of increase in MAP: esmolol $25 \% \pm 11 \%$, control $49 \%$ $\pm 19 \%$, lidocaine $55 \% \pm 26 \%$, nitroglycerin $45 \% \pm 21 \%$ (Singh et al. 1995). The second trial, comprised of a comparison of esmolol and nitroglycerin infusions, reflected similar conclusions which have been discussed at length above. The third trial also yielded results similar to the first two, demonstrating esmolol's superior efficacy, analyzing all HR and MAP data via the paired Student ttest, with all data falling within a significance level of $\mathrm{P}<0.001$, demonstrating an extraordinarily high level of significance. These results are consistent with the previously discussed trials. With each of the trials, nitroglycerin produced variable results in which attenuation of BP was noted, but attenuation of HR was not, with each of the trials demonstrating statistically significant results as previously discussed. In fact, in one study, higher levels of tachycardia were noted as compared to the control group. Both lidocaine and magnesium sulfate were ineffective in reduction of hemodynamic response, each with statistically significant results. 


\section{Conclusion}

In considering the initial question, "In adult patients undergoing the induction of anesthesia does esmolol as compared to nitroglycerin more effectively control hemodynamic responses (HR \& BP) during laryngoscopy and intubation?" the data is clear in demonstrating that esmolol is by far the more effective choice for controlling hemodynamic responses to laryngoscopy and intubation. Furthermore, the data displays that while an esmolol bolus is more effective in hemodynamic attenuation than any of the other drugs tested, an esmolol infusion is even more effective at attenuating the hemodynamic response for a longer period of time than a single bolus dose. In summary, esmolol is more efficacious at reducing hemodynamic responses than nitroglycerin, and is the clear drug of choice for this purpose if no contraindications exist.

\section{Acknowledgements}

I would like to thank Dr. Mark Welliver, whose input was invaluable in the construction of this review.

\section{References}

[1] Aghdaii N, Ziyaeifard M, Faritus SZ, Azarfarin R (2015) Hemodynamic responses to two different anesthesia regimens in compromised left ventricular function patients undergoing coronary artery bypass graft surgery: etomidate-midazolam versus propofolketamine. Anesthesiology and Pain Medicine. 5, e27966. http://dx.doi.org/10.5812/aapm.27966v2.

[2] Gelman A, Stern H. (2006) The difference between "significant" and "not significant" is not itself statistically significant. The American Statistician. 60, 328-331. http://dx.doi.org/10.1198/000313006X152649.

[3] Go AS, Mozaffarian D, Roger VL, Benjamin EJ, Berry JD, Borden WB, Bravata DM, Dai S, Ford ES, Fox CS, Franco S, Fullerton HJ, Gillespie C, Hailpern SM, Heit JA, Howard VJ, Huffman MD, Kissela BM, Kittner SJ, Lackl and DT, Lichtman JH, Lisabeth LD,
Magid D, Marcus GM, Marelli A, Matchar DB, McGuire DK, Mohler ER, Moy CS, Mussolino ME, Nichol G, Paynter NP, Schreiner PJ, Sorlie PD, Stein J, Turan TN, Virani SS, Wong ND, Woo D, Turner MB; American Heart Association Statistics Committee and Stroke Statistics Subcommittee. (2013) Heart disease and stroke statistics-2013 update: a report from the American Heart Association. Circulation. 127, e6-e245. http://dx.doi.org/10.1161/CIR.0b013e31828124ad.

[4] Gupta P, P anda B, Verma R, Ranjan P, Mathur S, Sinha G. (2009) Attenuation of haemodynamic responses to laryngoscopy \& intubation following nitroglycerin and esmolol infusion. The Internet Journal of Anesthesiology. 22, e1-e5.

[5] Joanna Briggs Institute. New JBI levels of evidence. (2013) Available at: http://joannabriggs.org/assets/docs/approach/JBILevels-of-evidence_2014.pdf (accessed 18 October 2015).

[6] Kovac AL (1996) Controlling the hemodynamic response to laryngoscopy and endotracheal intubation. Journal of Clinical Anesthesia. 8, 63-79. http://dx.doi.org/10.1016/09528180(95)00147-6.

[7] Reid LC, Brace DE (1940) Irritation of the respiratory tract and its reflex effect upon heart. Surgery, Gynaecology, Obstetrics. 70, 157 162.

[8] Sarkılar G, Sargın M, Sarıtas TB, Borazan H, Gök F, Kılıçaslan A, Otelcioğlu Ş (2015) Hemodynamic responses to endotracheal intubation performed with video and direct laryngoscopy in patients scheduled for major cardiac surgery. International Journal of Clinical and Experimental Medicine. 8, 11477-11483. PMCID: PMC4565349.

[9] Singh H, Vichitvejpaisal P, Gaines GY, White PF. (1995) Comparative effects of lidocaine, esmolol, and nitroglycerin in modifying the hemodynamic response to laryngoscopy and intubation. Journal of Clinical Anesthesia. 7, 5-8. http://dx.doi.org/10.1097/00132586-199602000-00054.

[10] van den Berg AA, Savva D, Honjol NM. (1997) Attenuation of the haemodynamic responses to noxious stimuli in patients undergoing cataract surgery. A comparison of magnesium sulphate, esmolol, lignocaine, nitroglycerine and placebo given i.v. with induction of anaesthesia. European Journal of Anaesthesiology. 14, 134-147. PMID: 9088811. http://dx.doi.org/10.1097/00003643-199703000$\underline{00004}$.

\section{Appendix I}

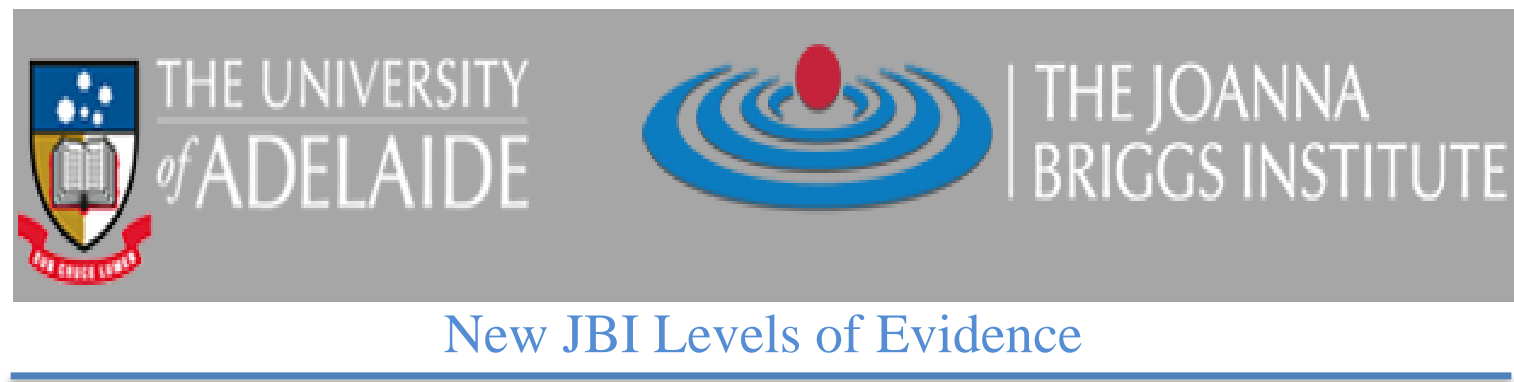

Developed by the Joanna Briggs Institute Levels of Evidence and Grades of Recommendation Working Party October 2013

PLEASE NOTE: These levels are intended to be used alongside the supporting document outlining their use. Using Levels of Evidence does not preclude the need for careful reading, critical appraisal and clinical reasoning when applying evidence.

\section{LEVELS OF EVIDENCE FOR EFFECTIVENESS}

Level 1 - Experimental Designs

Level 1.a - Systematic Review of Randomized Controlled Trials (RCTs)

Level 1.b - Systematic review of RCTs and other study designs

Level 1.c-RCT

Level 1.d - Pseudo-RCTs

Level 2 - Quasi-experimental Designs

Level 2.a - Systematic review of quasi-experimental studies

Level 2.b - Systematic review of quasi-experimental and other lower study designs

Level 2.c - Quasi-experimental prospectively controlled study

Level 2.d - Pre-test - Post-test or historic/retrospective control group study

Level 3 - Observational - Analytical Designs

Level 3.a - Systematic review of comparable cohort studies

Level 3.b - Systematic review of comparable cohort and other lower study designs

Level 3.c - Cohort study with control group 
Level 3.d - Case - controlled study

Level 3.e - Observational study without a control group

Level 4 - Observational - Descriptive Studies

Level 4.a - Systematic review of descriptive studies

Level 4.b - Cross-sectional study

Level 4.c - Case series

Level 4.d - Case Study

Level 5 - Expert Opinion and Bench Research

Level 5.a - Systematic review of expert opinion

Level 5.b - Expert consensus

Level 5.c - Bench research/single expert opinion

\begin{tabular}{|c|c|c|c|c|c|}
\hline Source & $\begin{array}{l}\text { Study } \\
\text { Design/ } \\
\text { Sample } \\
\text { Size }\end{array}$ & $\begin{array}{l}\text { Type of } \\
\text { Patients/ } \\
\text { Surgery Type }\end{array}$ & Test Strategy & $\begin{array}{l}\text { Measured End- } \\
\text { points }\end{array}$ & Results \\
\hline $\begin{array}{l}\text { Singh et } \\
\text { al, } 1995\end{array}$ & $\begin{array}{l}\text { RCT } \\
\text { (Double } \\
\text { Blinded) } \\
\text { Sample } \\
\text { Size } \\
40\end{array}$ & $\begin{array}{l}\text { ASA I \&II/ } \\
\text { General sur- } \\
\text { gery }\end{array}$ & $\begin{array}{l}\text { Group } 1 \text { (Control): } \\
\text { Normal Saline } 5 \mathrm{ml} \text { at } \\
\mathrm{t}=0 \mathrm{~min} \text {. } \\
\text { Group 2: Lidocaine } \\
1.5 \mathrm{mg} / \mathrm{kg} \text { at } \mathrm{t}=1 \mathrm{~min} \\
\text { Group 3: Esmolol } 1.4 \\
\mathrm{mg} / \mathrm{kg} \text { at } \mathrm{t}=2 \mathrm{~min} \\
\text { Group 4: Nitroglycer- } \\
\text { in } 2 \mu \mathrm{g} / \mathrm{kg} \text { at } \mathrm{t}=3 \mathrm{~min}\end{array}$ & $\begin{array}{ll}\bullet & \mathrm{HR} \\
\bullet & \mathrm{MAP} \\
\bullet & \mathrm{O}_{2} \text { Sat } \\
- & \text { ECG Lead } \\
& \mathrm{V}_{5}\end{array}$ & $\begin{array}{l}\text { Esmolol was consistently and markedly better at moderating } \\
\text { both MAP and HR increases (MAP: } 25 \% \pm 11 \% \text {; HR: } 20 \% \pm \\
3 \% \text { ) sustained during laryngoscopy and intubation as compared } \\
\text { to the control (MAP: } 49 \% \pm 19 \% \text {; HR: } 29 \% \pm 4 \% \text { ), lidocaine } \\
\text { (MAP: } 55 \% \pm 26 \% \text {; HR: } 52 \% \pm 8 \% \text { ), or nitroglycerin (MAP: } \\
45 \% \pm 21 \% \text {; HR: } 37 \% \pm 8 \% \text { ) groups, each which demonstrated } \\
\text { virtually no effect on hemodynamic moderation. }\end{array}$ \\
\hline $\begin{array}{l}\text { Gupta et } \\
\text { al, } 2009\end{array}$ & $\begin{array}{l}\text { RCT } \\
\text { Sample } \\
\text { Size } \\
60\end{array}$ & $\begin{array}{l}\text { ASA I \&II/ } \\
\text { Any surgery } \\
\text { requiring } \\
\text { general anes- } \\
\text { thesia }\end{array}$ & $\begin{array}{l}\text { Group C (Control): } \\
\text { Normal Saline at } 5 \\
\text { min prior to intubation } \\
\text { Group E: Esmolol } \\
\text { hydrochloride infusion } \\
100 \mathrm{mcg} / \mathrm{kg} / \mathrm{min} \text { at } 5 \\
\text { min prior to intubation } \\
\text { Group N: Nitroglycer- } \\
\text { in infusion } 0.5 \\
\text { mcg/kg/min at } 5 \text { min } \\
\text { prior to intubation }\end{array}$ & $\begin{array}{ll}\text { - } & \text { HR } \\
\text { - } & \text { SBP } \\
\text { - } & \text { DBP } \\
\text { - } & \text { MAP }\end{array}$ & $\begin{array}{l}\text { Esmolol was more effective in every measured category at } \\
\text { attenuating hemodynamic responses to laryngoscopy and intu- } \\
\text { bation (changes in HR after intubation were statistically not } \\
\text { significant; MAP decreased significantly } 1 \text { minute after intuba- } \\
\text { tion (p<0.05) and increased minimally thereafter, but was not } \\
\text { significantly different from the initial value) than either normal } \\
\text { saline [HR increased } 1 \text { min after intubation ( } p<0.01 \text { ) and } 3 \text { and } \\
4 \text { min after intubation ( } \mathrm{p}<0.001) \text {; MAP increased significantly } \\
\text { in the control group following intubation after } 1 \text { min ( }<<0.01) \\
\text { as well as after } 3 \text { and } 5 \text { min }(<0.001) \text { or nitroglycerin }[\mathrm{HR} \\
\text { increased } 1 \text { min after intubation and continued to increase at } 3 \text {, } \\
4 \text { and } 5 \text { minutes after intubation }(\mathrm{p}<0.05) \text {; the rise in MAP was } \\
\text { statistically significant only } 3 \text { min after intubation }(\mathrm{p}<0.001)] \text {. }\end{array}$ \\
\hline $\begin{array}{l}\text { van den } \\
\text { Berg et } \\
\text { al, } 1997\end{array}$ & $\begin{array}{l}\text { RCT } \\
\text { Sample } \\
\text { Size } \\
100\end{array}$ & $\begin{array}{l}52 \text { healthy; } \\
48 \text { with a } \\
\text { preexisting } \\
\text { condition/ } \\
\text { Cataract sur- } \\
\text { gery }\end{array}$ & $\begin{array}{l}\text { Group } 1 \text { (Control): } \\
\text { Normal Saline at } \\
\text { induction of anesthe- } \\
\text { sia } \\
\text { Group } 2 \text { : Magnesium } \\
\text { sulfate } 40 \mathrm{mg} / \mathrm{kg} \text { at } \\
\text { induction of anesthe- } \\
\text { sia } \\
\text { Group 3: Esmolol } 4.0 \\
\text { mg/kg at induction of } \\
\text { anesthesia } \\
\text { Group } 4 \text { : Lignocaine } \\
\text { (lidocaine) } 1.5 \text { mg/kg } \\
\text { at induction of anes- } \\
\text { thesia } \\
\text { Group 5: Glyceryl } \\
\text { trinitrate (nitroglycer- } \\
\text { in) } 7.5 \text { mcg/kg at } \\
\text { induction of anesthe- } \\
\text { sia }\end{array}$ & $\begin{array}{ll}- & \mathrm{HR} \\
\bullet & \mathrm{BP} \\
\text { - } & \mathrm{RPP} \\
- & \mathrm{PRQ}\end{array}$ & $\begin{array}{l}\text { Esmolol was the most effective at preventing rises in HR } \\
(\mathrm{P}<0.001) \text { and } \mathrm{RPP}(\mathrm{P}<0.001) \text {. Nitroglycerin prevented a rise } \\
\text { in } \mathrm{RPP}(\mathrm{P}<0.001) \text {, but also resulted in a tachycardia above that } \\
\text { demonstrated in the control group, as well as a fall in } \mathrm{PRQ} \text { to }< \\
\text { 1.0. Magnesium sulfate }(\mathrm{P}<0.001) \text { and lidocaine }(\mathrm{P}<0.001) \\
\text { were equally ineffective in preventing rises in hemodynamic } \\
\text { response. Researchers set significance values of } \mathrm{P}<0.05 \text {, how- } \\
\text { ever significance levels of } \mathrm{P}<0.001 \text { were found in all statistical } \\
\text { calculations, proving all results to be of substantial statistical } \\
\text { significance }\end{array}$ \\
\hline
\end{tabular}

